This is the author's version of a work that was published in the following source:

Babrowski, S.; Jochem, P.; Fichtner, W. (2016)

How to model the cycling ability of thermal units in power systems?

Energy, 103, 397-409

doi:10.1016/j.energy.2016.02.142

Please note: Copyright is owned by the author(s) and / or the publisher. The commercial use of this copy is not allowed. 


\title{
HOW TO MODEL THE CYCLING ABILITY OF THERMAL UNITS IN POWER SYSTEMS
}

[Sonja Babrowski, Tel. +49 721608 44676, sonja.babrowski@kit.edu] [Patrick Jochem, patrick.jochem@ kit.edu]

[Wolf Fichtner, wolf.fichtner@kit.edu] Karlsruhe Institute of Technology (KIT), Institute for Industrial Production (IIP), Chair of Energy Economics, Hertzstr. 16, Building 06.33, D-76187 Karlsruhe, Germany, Fax: +49 721 608-44682

\begin{abstract}
For thermal units in power systems, the importance of quick load changes increases along with the share of volatile renewable feed-in. An adequate representation of the cycling abilities of thermal units is therefore important in energy system modeling. Five different model techniques used in the literature to describe the cycling ability of thermal generation units are applied in the optimizing energy system model PERSEUS-NET-TS. The model calculates the dispatch of German generation units while restrictions of the transmission grid are considered. Differences in the cumulated dispatch of coal, lignite, and gas combinedcycle units in Germany due to the different modeling techniques are analyzed based on the PERSEUS-NET$T S$ results as well as the resulting dispatch of two exemplary single generation units. While the cumulated dispatch for Germany does not show any major differences for coal and lignite units, the cumulated dispatch of gas units differs slightly depending on the approach. Moreover, the dispatch of individual generation units may differ significantly. Even though the real commissioning strategies are not publicly known, it could be identified that the mostly applied modeling approaches based on technical restrictions increase computing time unnecessarily and that cost based approaches reduce on/off cycling more.
\end{abstract}

\section{Keywords:}

Unit Commitment; Energy System Modeling; Cycling; Load Changes; Thermal Generation

\section{Introduction}

In power systems with an increasing amount of feed-in by volatile RES (renewable energy sources), there is a growing importance of quick load changes for the remaining fossil-fueled generation units [1]. Adjusting the unit output in order to meet the residual demand at any time, i.e. cycling, is important for a secure electricity supply [1]. An adequate representation of the cycling or load-changing abilities of fossilfueled thermal units is therefore increasingly important in optimizing energy system models. For technical reasons, gas turbines (typical peak load units), for example, can cope better with load changes than most coal or, especially, lignite generating units (typical base load units). The start-up or ramping rate of thermal generation units is generally limited by thermal stress and resulting pressure differences [2]. Additionally, costs induced by load changes have to be considered. Load changes or cycling lead to increasing maintenance and repair costs due to creep and fatigue [3]. Emissions also in-crease through cycling. Especially during the start-up phase, additional costs and emissions occur [4]. According to Schroder€ et al. [2], there are three reasons for additional costs: Firstly, the additional fuel and manpower needed during the start-up phase. Secondly, an increased depreciation of the generation unit, and thirdly, higher fuel 
Postprint of the article How to model the cycling ability of thermal units in power systems? in Energy, 103, 397-409. doi:10.1016/i.energy.2016.02.142

consumption due to a lower efficiency during the ramping phase. Modeling start-up costs may significantly improve the results of production cost models and makes them more realistic [5]. Costs for load changes while running also exist, but are significantly lower [6]. They are, among other things, due to abrasion and differ for all generation units because of the fuel type, different materials, outdated power plant design, operation, maintenance, and repair history [7]. Another technical restriction is the minimum power (i.e. minimum generation when running). It is not possible to operate at a level below that limit due to technical restrictions such as insufficient temperatures and/or excessive emissions [8]. To avoid putting too much thermal stress on the material, ramping rates are often specified for different generation units.

Different ways of modeling the cycling ability of thermal units for optimizing energy system models are described in the literature. Consideration of the minimum power (e.g. Ref. [9]) is comparatively easy to implement but comes with the cost of needing binary variables and thus with a mixed-integer calculation. One rather common way of mapping unit cycling in unit commitment, respectively dispatch models is by a combination of the minimum power with a minimum up-time and a minimum down time (e.g. Ref. [5] or [10]). Similar approaches introduce further constraints such as minimum cycle time [11] or limited ramping rates and start-up costs [12]. Hundt et al. [13] give technology-specific values for these constraints but argue that minimum up-and down-times are no purely technical but rather economic restrictions. Their application shall prevent the modeled generation units from performing too many load changes. However, as stated before, in optimizing models, this approach has the disadvantage of needing binary variables that lead to a mixed-integer problem. Accordingly, the calculation time of the considered optimization problem may rise tremendously. This makes it difficult to apply these modeling techniques if calculation time is crucial, as for example in stochastic models [14]. In that case, a linear description of the cycling abilities of thermal units is preferable. One linear description is the application of costs to any positive or negative load change (e.g. Ref. [15]). Yet another approach is the use of a linear description of start-up costs [16]. These costs only apply to positive load changes below the minimum power. Above the minimum power, there are no costs applied to further positive or negative load changes. Thus, the generation might rather remain at the minimum power for a few hours than be reduced below it and cause costs when generation is increased again later. The implementation of ramping rates in energy system models is also applied (e.g. Ref. [17]). Norouzi et al. [18] even consider dynamic ramp-rates and ramp-down limits. De Jonghe et al. [19] give technology-specific values and apply an illustrative example. Some recent studies include even more constraints [20], e.g. combine these ramping rates with minimum up- and down-times, and start-up costs (differing in accordance with warm or cold start) [21] as well as cold start time (e.g. Ref. [22]). However, modeling these in dispatching energy system models seems only useful with a time resolution that is finer than hourly [23].

So far, no comprehensive comparison of different approaches to modeling these flexibility constraints is given in the literature (or even a comparison with results neglecting these constraints). In order to understand the resulting inflictions, in this paper differences in the unit commitment are analyzed by applying five different approaches to depict the cycling ability of thermal units within the deterministic energy system model PERSEUS-NET-TS [24]. The following approaches are considered:

M1 Minimum power

M2 Minimum power in combination with minimum up- and down-time

M3 Costs on all load changes

M4 Costs on positive load changes below the minimum power (start-up costs) 
M5 Combination of start-up costs and costs on all load changes

M0 No consideration of any cycling costs or restrictions

The resulting unit dispatches based on these approaches are compared to each other and to a model run where restrictions and costs of load-changing are totally neglected (M0). Consequently, in the next section, an overview of the optimization model PERSEUS-NET-TS is given. The third section focuses on the integration of the different ways of mapping the cycling ability. In Section 4, the resulting dispatches of the thermal units (lignite, coal, combined-cycle gas turbines (CCGT), and gas turbines) are compared to each other and to a dispatch without considering any restrictions of the cycling ability. A conclusion is given in the last section (5).

\section{The energy system model PERSEUS-NET-TS}

The optimizing energy system model PERSEUS-NET-TS [24] is used to evaluate the advantages and drawbacks of the five different approaches to modeling the cycling ability. In principle, the myopic model is able to calculate the investment and dispatch plans for thermal generation plants in the German energy system up to 2040. Starting with the base year 2012, at least every fifth year is calculated and thereby represented through an hourly mapping of one week for each season (672 h). For the task of analyzing how the cycling ability is modeled best, only the dispatch of existing generation units of the first period (i.e. 2012) is considered in this paper. Therefore, only equations and parameters relevant to calculating the dispatch of the generation units in the first period are described here and not those relevant to the commissioning of new generation units.

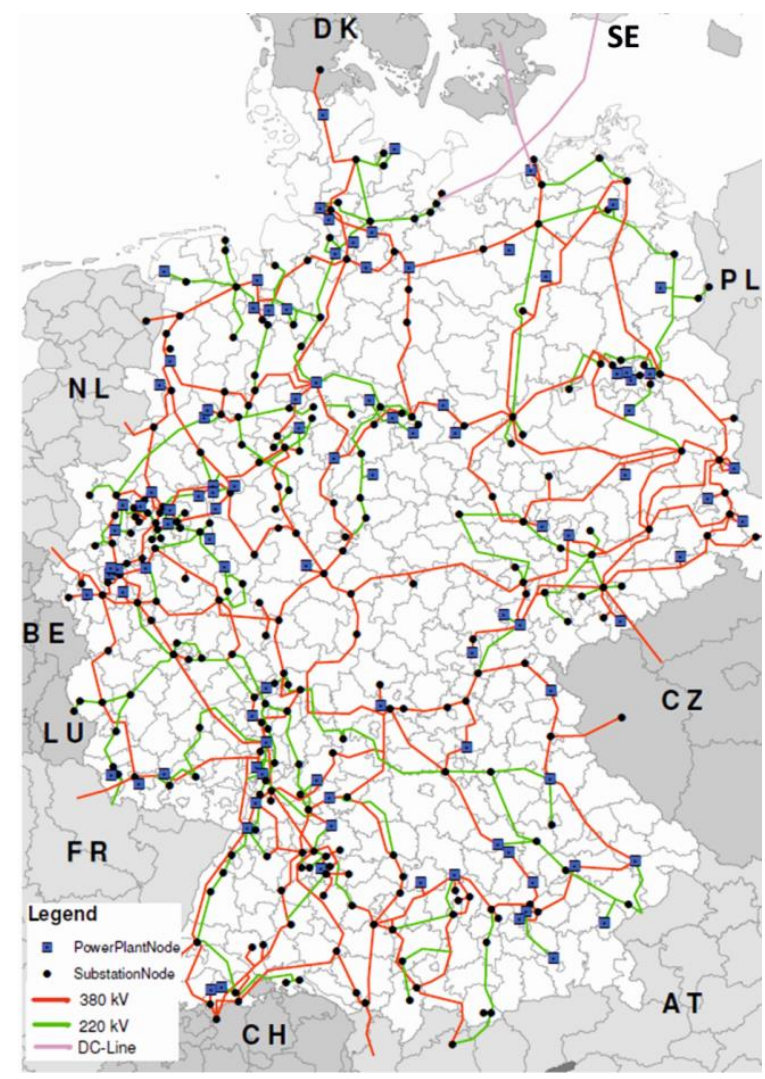

Fig. 1 PERSEUS-NET-TS system boundaries (Germany) [15]

The model maps the German energy system and includes a nodal pricing approach based on a DC calculation of the German trans-mission grid. Over 440 nodes and over 500 lines (360 and $220 \mathrm{kV}$ ) are 
Postprint of the article How to model the cycling ability of thermal units in power systems? in Energy, 103, 397-409. doi:10.1016/i.energy.2016.02.142

considered with their technical characteristics (see Fig. 1). About 260 large generation units (>100 MW) are depicted individually and allocated at their specific grid nodes. Smaller generation units are accumulated for each grid node. The driving force of the model is the exogenously given demand that has to be satisfied at each considered hour and each grid node whilst the system-relevant expenditures are minimized (see Fig. 2). This can either be done by electricity generation in the generation units assigned to that grid node or by electricity transfer via the transmission grid.
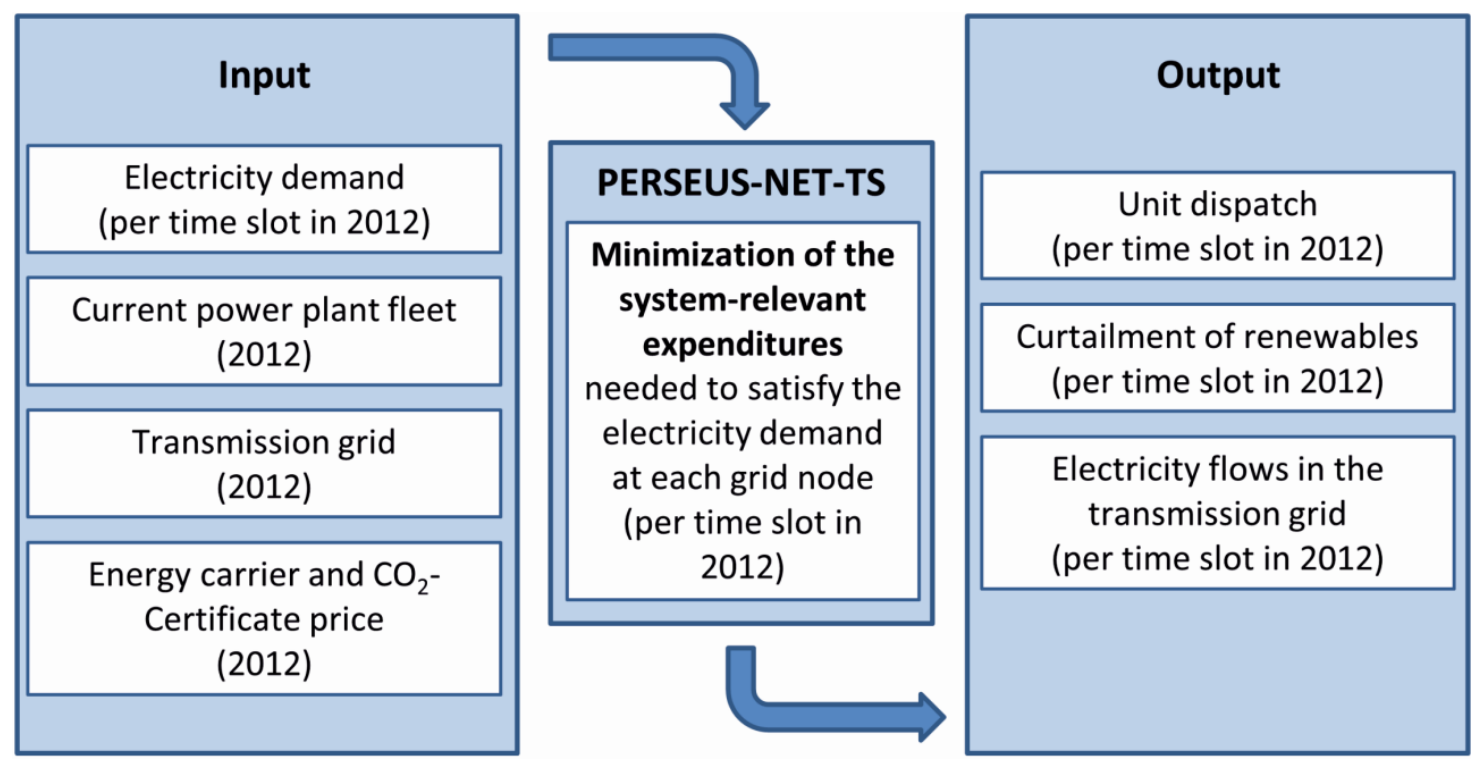

Fig. 2 Applied PERSEUS-NET-TS features

The PERSEUS-NET-TS model is structured as a graph in which so-called producers $(p d \in P D)^{1}$ form the nodes and flows of different energy carriers $(e c \in E C)$ form the edges in between $\left(F S_{p d, p d^{\prime}, e c, t}\right.$ (hourly

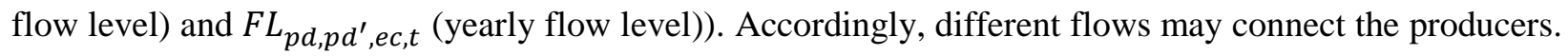
Consequently, the grid nodes of the transmission grid are modeled as producers that may be connected to each other through electricity flows. Producers may have different (generation) units $(u \in U)$ assigned to them. These units may then have different processes $(p c \in P C)$. Imports from outside the system boundaries are the sources of the graph $(i p \in I P \subset P D)$ and correspond to fuel purchases of some producers. Exports are the sinks of the graph $(e p \in E P \subset P D)$ and correspond to electricity demand processes.

The expenditures in the objective function (cf. Equation 1) are composed of costs related to energy carriers, electricity generation processes, and generation units. The energy carrier-related costs are the costs for fuel supply $\left(C_{i p, p d, e c, t}^{\text {Fuel }}\right)$ times the level of the fuel import flow to the considered producer $F L_{i p, p d, e c, t}$. Fuel costs for thermal units already include additional costs for $\mathrm{CO}_{2}$ emissions and are based on [25]. Variable costs $\left(C_{p c, t}^{V a r}\right)$ for electricity generation $\left(P L_{p c, t}\right)$ are considered for each generation process as well as, if applicable, some kind of cycling costs $\left(C_{p c, t, s-1, s}^{L C}\right)$ from one time slice to the next $(s \in S)$. Additionally, fixed costs $\left(C_{u, t}^{F i x}\right)$ for existing generation units $\left(\operatorname{Cap}_{u, t}^{T o t}\right)$ and investments $\left(C_{u, t}^{I n v}\right)$ in new generation units $\left(C a p_{u, t}^{N e w}\right)$ are considered. As for 2012 the existing power plant portfolio is known and no further capacities are needed

${ }^{1}$ A complete nomenclature can be found in the appendix. 
for satisfying the electricity demand, $\operatorname{Cap}_{u, t}^{N e w}$ equals zero for the following analyses. Consequently, the costs related to the existence of units are not decision-relevant in this context.

$\forall t \in T \subset\{2012\}$

$$
\min \left[\begin{array}{c}
\left(\sum_{e c \in E C} \sum_{i p \in I P} \sum_{p d \in P D} F L_{i p, p d, e c, t} \cdot C_{i p, p d, e c, t}^{F u e l}\right) \\
+\sum_{p c \in P C}\left(\begin{array}{c}
P L_{p c, t} \cdot C_{p c, t}^{V a r} \\
+\sum_{s \in S} C_{p c, t, s-1, s}^{L C}
\end{array}\right) \\
+\sum_{u \in U}\left(\begin{array}{c}
\operatorname{Cap}_{u, t}^{T o t} \cdot C_{u, t}^{F i x} \\
+\operatorname{Cap}_{u, t}^{N e w} \cdot C_{u, t}^{I n v}
\end{array}\right)
\end{array}\right]
$$

For each grid node, the model balances the material and energy flows for each of the 672 considered hours or time slots, respectively. The electricity $(e l \in E C)$ flows are balanced for each time slot through Equation 2. For each time slot, the levels of inflows from neighboring grid nodes $\left(F S_{p d^{\prime}, p d, e l, t, s}\right)$ plus the electricity generation $\left(P S_{p c, t, s} \cdot \lambda_{p c, e l}\right)$ at the grid node equal the outflows $\left(F S_{p d, p d^{\prime}, e l, t, s} ; F S_{p d, e p, e l, t, s}\right)$ and use of electricity $\left(P S_{p c, t, s} \cdot \lambda_{p c, e l}\right)$ at this grid node. The efficiencies of the flows and the use process $\left(\eta_{p d, p d^{\prime}, e l, t}, \eta_{p d, e p, e l, t}, \eta_{\mathrm{pc}, \mathrm{t}}\right)$ are also considered. The output parameter $\lambda_{p c, e l}$ for each process describes whether electricity is an input $\left(\lambda_{p c, e l}=-1\right)$ or an output $\left(\lambda_{p c, e l}=1\right)$. It has to be noted that the energy carrier "electricity" cannot be imported from outside of the system boundaries, meaning that it is not possible to buy electricity from neighboring countries or from generation units not depicted in the model. This might not necessarily be realistic; however it does not interfere with resulting differences due to different modeling techniques which are analyzed in this paper.

$$
\begin{aligned}
& \sum_{p d^{\prime} \in P D} F S_{p d^{\prime}, p d, e l, \mathrm{t}, \mathrm{s}}+\sum_{p c \in P C_{p d}^{G}} P S_{p c, t, s} \cdot \lambda_{p c, e l} \\
= & \sum_{p d^{\prime} \in P D} \frac{F S_{p d, p d^{\prime}, e l, t, s}}{\eta_{p d, p d^{\prime}, e l, t}}+\sum_{e p \in E P} \frac{F S_{p d, e p, e l, t, s}}{\eta_{p d, e p, e l, t}}-\sum_{p c \in P C} P S_{p c, t, s} \cdot \frac{\lambda_{p c, e l}}{\eta_{p c, t}}
\end{aligned}
$$

$\forall t \in T ; \forall s \in S ; \forall p d \in P D ; \forall e l \in E C$

The exogenously given electricity demand $\left(D_{p d, e l, t, s}\right)$ at each grid node for each considered hour is depicted within the model as an electricity flow to outside of the system boundaries ( $\left.F S_{p d, e p, e l, t, s}\right)$ (cf. Equation 3). A net electricity demand of $527 \mathrm{TWh}$ is considered for the year 2012 [26]. Its distribution to the over 400 different grid nodes is based on a bottom-up calculation considering regional GDP and population [15].

$$
F S_{p d, e p, e l, t, s}=D_{p d, e l, t, s}
$$

$\forall t \in T ; \forall s \in S ; \forall p d \in P D ; \forall e p \in E P$

Unlike electricity, primary energy carriers $\left(E C^{T}\right)$ such as uranium, lignite, coal or gas, are only balanced once per period (cf. Equation 4) instead of hourly. However, these energy carriers may be imported from 
Postprint of the article How to model the cycling ability of thermal units in power systems? in Energy, 103, 397-409. doi:10.1016/i.energy.2016.02.142

outside the system boundaries. Consequently, the yearly import flow of an energy carrier to a producer $\left(F L_{i p, p d, e c, t}\right)$ and the flows from other producers $\left(F L_{p d^{\prime}, p d, e c, t}\right)$ plus the generation of the energy carrier in processes $\left(P L_{p c, t}\right)$ have to equal the yearly flows to other producers $\left(F L_{p d, p d^{\prime}, e c, t}\right)$ or to the outside of the system boundaries $\left(F L_{p d, e p, e c, t}\right)$ plus the yearly use of the energy carrier in demand processes $\left(P L_{p c, t}\right)$. The resulting import flows of uranium, lignite, coal, and gas as well as biomass are weighted with fuel costs in the objective function (cf. Equation 1).

$$
\begin{aligned}
& \sum_{i p \in I P} F L_{i p, p d, e c, t}+\sum_{p d^{\prime} \in P D} F L_{p d^{\prime}, p d, e c, t}+\sum_{p c \in P C_{p d}^{G}} P L_{p c, t} \cdot \lambda_{p c, e c} \\
& =\sum_{p d^{\prime} \in P D} \frac{F L_{p d, p d^{\prime}, e c, t}}{\eta_{p d, p d^{\prime}, e c, t}}+\sum_{e p \in E P} \frac{F L_{p d, e p, e c, t}}{\eta_{p d, e p, e c, t}}-\sum_{p c \in P C_{p d}^{D}} P L_{p c, t} \cdot \frac{\lambda_{p c, e c}}{\eta_{p c, \mathrm{t}}}
\end{aligned}
$$

$\forall t \in T ; \forall p d^{\prime}, p d \in P D ; \forall e c \in E C^{T}$

The two balancing equations (Equations 2 and 4) are complemented by an equation stating that the sum of the process level over all time slots has to equal the yearly process level (cf. Equation 5). Another equation states the same for the flow levels (cf. Equation 6).

$\forall t \in T ; \forall p c \in\left(P C \backslash P C_{E C^{V}}\right)^{2}$

$$
\sum_{s \in S} P S_{p c, t, s}=P L_{p c, t}
$$

$\forall t \in T ; \forall p d^{\prime}, p d \in P D$

$$
\sum_{s \in S} F S_{p d^{\prime}, p d, e c, \mathrm{t}, \mathrm{s}}=F L_{p d^{\prime}, p d, e c, t}
$$

Additionally, there are restrictions about the operation of the installed generation units. Equation 7 guarantees that in a certain hour, only as much electricity is generated in each generation process as the installed capacity $\left(\mathrm{Cap}_{u, t}^{T o t}\right)$ of that process allows. The installed capacity of the unit is reduced by an availability factor $\left(A_{u, t}\right)$ and multiplied by the weighting of the considered time slot $\left(Z_{s}\right)$. For thermal units, this installed power is reduced by an availability factor between 84 and $89 \%$, depending on the fuel type (based on [2]). There are also availability factors applied to biomass (80\%) and running-water units (63\%).

$$
\sum_{\mathrm{p} c \in P C_{u}} P S_{p c, s, t} \leq C a p_{u, t}^{T o t} \cdot A_{u, t} \cdot Z_{s}
$$

with:

$\sum_{s} Z_{s}=8760$

$\forall t \in T ; \forall s \in S ; \forall u \in U$

\footnotetext{
${ }^{2}$ The exception for the volatile energy carriers is explained in Equation 9.
} 
Generation processes may also be limited by maximum full-load hours $\left(V l h_{u, t}^{M a x}\right)$ per year (cf. Eq.8). In the model used for this analysis, this is the case for wind (about 1,800 hours) and photovoltaic units (about 870 hours). These values are based on historical values, the precise derivation is described in [27].

$\forall t \in T ; \forall u \in U$

$$
\sum_{p c \in P C_{u}} P L_{p c, t} \leq V l h_{u, t}^{M a x} \cdot \operatorname{Cap}_{u, t}^{T o t}
$$

The upper limit for electricity generation from the volatile energy sources $\left(e c v \in E C^{V} \subset E C\right)$ wind and solar is given by Equation 9, where $X_{e c v, s}$ determines the share of the yearly generation that is available at a considered time slot. The feed-in from PV and wind units is based on historical feed-in data of the four German network system operators (i.e. Tennet [28], 50Hertz [29], Amprion [30], and TRANSNET [31]). It can be curtailed in case that oversupply or bottlenecks occur. Because of this, Equation 5 is not applied to processes with volatile energy carriers (i.e. wind and photovoltaic).

with:

$$
P S_{p c, s, t} \leq P L_{p c, t} \cdot X_{e c v, s}
$$

$\sum_{s} X_{e c v, s}=1$

$\forall t \in T ; \forall s \in S ; \forall p c \in P C_{e c v} ; \forall e c v \in E C^{V}$

The power flows between grid nodes in PERSEUS-NET-ESS are subject to restrictions based on the DC approximation of the German transmission network and its thermal limits. A comprehensive deviation from the theory of the DC representation [32] using a Benders decomposition approach from [33] is given in [15]. .

$$
\sum_{e l \in E C} \frac{F L_{y, y^{\prime}, e l, \mathrm{t}, \mathrm{s}}}{Z_{s}}=\gamma_{y, y^{\prime}} \cdot\left(\theta_{y, t, s}-\theta_{y^{\prime}, t, s}\right)
$$

According to the DC representation, the active power flow $\left(F L_{y, y^{\prime}, e l, t, s}\right)$ over the transmission line from one grid node $(y \in Y)$ to another grid node $\left(y^{\prime} \in Y\right)$ has to equal the product of the susceptance of the line $\left(\gamma_{\mathrm{y}, \mathrm{y}^{\prime}}\right)$ and the phase angle difference $\left(\theta_{\mathrm{y}, \mathrm{t}, \mathrm{s}}-\theta_{\mathrm{y}^{\prime}, \mathrm{t}, \mathrm{s}}\right)$ of the two grid nodes at any time (cf. Equation 10). In doing so, grid nodes are modeled as a subset of the producers $(\mathrm{y} \in \mathrm{Y} \subset P D)$ and are subsequently balanced over Equation 3. For a reference level, one grid node has to be defined as slack bus with a phase angle difference of zero (cf. Equation 11).

$\forall y \in Y ; \forall t \in T ; \forall s \in S$

$$
\theta_{y, t, s} \cdot S L_{y}=0
$$

with $S L_{y}=\left\{\begin{array}{cc}1, & \text { if slack bus } \\ 0, & \text { oherwise }\end{array}\right.$

Additionally, the active flow in either direction over a line is restricted by the thermal limits $\left(T L_{y, y^{\prime}, t}\right)$ of the line (cf. Equation 12).

$\forall y, y^{\prime} \in Y ; \forall t \in T ; \forall s \in S$

$$
(-1) \cdot T L_{y, y^{\prime}, t} \leq \frac{F L_{y, y^{\prime}, e l, \mathrm{t}, \mathrm{s}}}{Z_{S}} \leq T L_{y, y^{\prime}, t}
$$


Postprint of the article How to model the cycling ability of thermal units in power systems? in Energy, 103, 397-409. doi:10.1016/i.energy.2016.02.142

If there is no sufficient transmission capacity between certain grid nodes, there might be a surplus of generated electricity on one side of the bottleneck and a shortage on the other side, leading to the use of more expensive plants and thus to different nodal prices. A comprehensive overview of the integrated nodal pricing approach is given by [15].

Restrictions concerning the installation of new capacities and storage systems complete the optimization model. The existing German pump hydro storage systems are depicted. Efficiencies are considered and the level of stored energy at the end of each depicted week has to match the level at the beginning of the same week [34]. The model is written in GAMS and solved with the commercial CPLEX solver. For more information on the PERSEUS-NET-TS structure and on other input data, please refer to [27].

\section{Modeling the cycling ability}

The mathematical description of the modeling techniques implemented in the PERSEUS-NET-TS model is given in the following sections. While the implementation of the minimum power is based on a linear mixed-integer approach (MILP), the implementation of costs on all load changes and costs on positive changes below the minimum power is linear (LP). Other combinations of the implemented approaches, as for example the combination of minimum up- and down-times with ramping rates and start-up costs (cf. e.g. [12]) and/or further methods to describe the cycling ability, are also possible but not further analyzed in this context.

\section{1 Minimum power (M1)}

With existing generation units, a minimum power can be defined when electricity is generated (M1). The unit can either generate with a power output above this minimum or not generate at all. The minimum power of coal units is assumed to be $38 \%$ of their installed capacity, for lignite units $40 \%$ and for combined-cycle units $33 \%$ [13]. The on/off status of a generation unit is described with the help of a binary variable $\left(G 01_{p c, t, s}\right)$, which is "1" when electricity is being generated and " 0 " when the unit is turned off. The binary variable is linked to the process level of the generating unit through Equation 13. The equation ensures that the variable $G 01_{p c, t, s}$ is " 1 " whenever electricity is generated. Another equation (Equation 14) states that the process level of any process and hour has to be above the minimum power $\left(M P S_{p c, t, s}\right)$ multiplied by the installed capacity and weighted by the quantity of occurrence whenever electricity is generated, i.e. $G 01_{p c, t, s}$ is " 1 ".

$$
P S_{p c, t, s} \leq \operatorname{Cap}_{u, t}^{T o t} \cdot Z_{s} \cdot G 01_{p c, t, s}
$$

$\forall p c \in P C_{t h} \subset P C ; \forall t \in T ; \forall s \in S$

$$
P S_{p c, t, s} \geq \operatorname{Cap}_{u, t}^{T o t} \cdot Z_{s} \cdot M P S_{p c, t, s} \cdot G 01_{p c, t, s}
$$

$\forall p c \in P C_{u} ; \forall u \in U_{t h} ; \forall t \in T ; \forall s \in S$ 


\section{2 Minimum up- and down-time (M2)}

In addition to the minimum power, minimum up- and down times can be implemented to limit the flexibility of thermal units (M2). These times do not exist in this way in reality and are rather economic values derived for the implementation in energy system models to prevent the modeled units from too many and too quick load changes [13].Consequently, the assumed minimum up- and down-times vary in different studies. For the analysis conducted in this paper, minimum up-times of four hours for coal units, four hours for CCGT units, and 6 hours for lignite units are assumed. For minimum down-times, two hours for coal units, one hour for combined cycle units, and six hours for lignite units. These numbers are based on Hundt et al. [13], but with the exception that the minimum down-time for CCGT units is reduced from two hours to one hour as most other studies see a more dynamic operation for CCGT units than for coal units [2]. These minimum up- and down times are modeled through Equations 15 and 16. With the minimum up-time, the on/off status $\left(G 01_{p c, t, s}\right)$ of the hours before the considered hour $\left(s^{\prime}\right)$ is summed up for the length of the minimum uptime $\left(U p_{p c}^{M i n}\right)$. For the case that the generation unit was on ("1") in the hour directly before the considered hour, the sum has to be larger than the minimum up-time when the on/off state shall be " 0 " in the considered hour (cf. Equation 15). For a minimum up-time of four hours that would mean that a generation unit that was turned on at 6 a.m. can only be turned off at the considered hour of 7 a.m. when the sum of the on/off states from 3 a.m. to 6 a.m. exceeds four. The minimum down-time $\left(D o_{p c}^{M i n}\right)$ is modeled analogously (cf. Equation 16).

$$
\sum_{s=s^{\prime}-U p_{p c}^{M i n}}^{s^{\prime}-1} G 01_{p c, t, s} \geq U p_{p c}^{M i n} \cdot\left(G 01_{p c, t, s^{\prime}-1}-G 01_{p c, t, s^{\prime}}\right)
$$

$\forall p c \in P C_{t h} \subset P C ; \forall t \in T ; \forall s, s^{\prime} \in S$

$$
\begin{aligned}
& \sum_{s=s^{\prime}-D o_{p c}^{M i n}}^{s^{\prime}-1}\left(1-G 01_{p c, t, s}\right) \geq D o_{p c}^{M i n} \cdot\left(G 01_{p c, t, s^{\prime}}-G 01_{p c, t, s^{\prime}-1}\right) \\
& \forall p c \in P C_{t h} \subset P C ; \forall t \in T ; \forall s, s^{\prime} \in S
\end{aligned}
$$

\section{3 Costs on all load changes (M3)}

A simple way to prevent generation units from performing too many load changes is to charge every change with costs (M3). This was done in former PERSEUS versions (cf. [35]), for example. The load change of a generation process between two hours is counted through the two positive variables $L C_{p c, s-1, s, t}^{u p}$ and $L C_{p c, s-1, s, t}^{d}$ and weighted by the quantity of how often this change of the considered hour to the next occurs within the chosen time structure $\left(N o_{s-1, s}\right)$ (cf. Eq.17). The level of load change in between the hours is then multiplied by the load-changing costs and subsequently considered in the objective function (cf. Eq.18 and Eq.1).

$$
L C_{p c, s-1, s, t}^{u p}-L C_{p c, s-1, s, t}^{d}=N o_{s-1, s} \cdot\left(\frac{P S_{p c, t, s}}{Z_{s}}-\frac{P S_{p c, t, s-1}}{Z_{s-1}}\right) \cdot \frac{1}{\eta_{p c, \mathrm{t}}}
$$

$\forall t \in T ; \forall s \in S ; \forall p c \in P C$ 


$$
C_{p c, t, s-1, s}^{L C}=\left(L C_{p c, s-1, s, t}^{u p}+L C_{p c, s-1, s, t}^{d}\right) \cdot C_{p c, t}^{L V}
$$

$\forall t \in T ; \forall s \in S ; \forall p c \in P C$

The level of these load-changing costs is difficult to determine and not many sources could be found in the literature. The costs used for the analyses presented are $1.96 \$ / \Delta \mathrm{MW}$ change for coal units and $0.64 \$ / \Delta \mathrm{MW}$ for CCGT units. These are based on the load-following costs given by Kumar et al. [6] and Lew et al. [36]. Another source for load-changing costs could not be found in the literature. Costs for load changes of lignite units are assumed to be slightly above the costs of coal units.

\section{4 Start-up costs - costs on positive load changes below the minimum power (M4)}

Another way to model cycling ability is by imposing costs on positive load changes below the minimum power, thus, by imposing some sort of start-up costs (M4). Once the generation unit has ramped up to the minimum power, no further costs occur as long as the load stays above the minimum power. To map these costs linearly, the load level is described by two additional positive variables between zero and one [16]. One variable $\left(P S_{p c, t, s}^{L o w}\right)$ serves to describe the load level between zero (turned off) and the minimum power $\left(\operatorname{Cap}_{u, t}^{T o t} \cdot M P S_{p c, t, s}\right)$. The second variable $\left(P S_{p c, t, s}^{H i g h}\right)$ describes the load level above the minimum power up to the maximum power $\left(\operatorname{Cap}_{u, t}^{T o t} \cdot A_{u, t}\right)$, i.e. the available installed net capacity. In case the unit generates at maximum power, both variables have to be " 1 ". In case the generation is at minimum power, it is sufficient if only the first variable is " 1 ". In case that no electricity is generated, both variables have to be " 0 " (cf. Equation 19). Furthermore, at all considered hours, the second variable $\left(P S_{p c, t, s}^{H i g h}\right)$ is smaller than or equal to the first variable $\left(P S_{p c, t, s}^{L o w}\right)$ (cf. Equation 20). Positive changes of the first variable in between subsequent hours are accounted for with the help of a third positive variable between zero and one $\left(S U C_{p c, t, s}\right)$ (cf. Equation 21). This variable is then multiplied by process-specific start-up costs $\left(C_{p c, t}^{S u p}\right)$ and thus indirectly considered in the objective function (cf. Equation 22).

It has to be noted that this linear formulation does not completely prevent generation units from generating below the minimum power. Also, it would be possible to generate at a level between the minimum and maximum power without being charged the full start-up costs as those are only applied when the unit operates at maximum power in a considered time slot. However, as soon as a generation unit is once operated at the maximum power, a temporary reduction of the production below the minimum power is costly and consequently rather avoided.

$$
P S_{p c, t, s}^{L o w} \cdot \operatorname{Cap}_{u, t}^{T o t} \cdot M P S_{p c, t, s}+P S_{p c, t, s}^{H i g h} \cdot \operatorname{Cap}_{u, t}^{T o t} \cdot\left(A_{u, t}-M P S_{p c, t, s}\right)=\frac{P S_{p c, t, s}}{Z_{s}}
$$

$\forall p c \in P C_{u} ; \forall u \in U_{t h} ; \forall t \in T ; \forall s \in S$

$$
P S_{p c, t, s}^{L o w} \geq P S_{p c, t, s}^{H i g h}
$$

$\forall p c \in P C ; \forall t \in T ; \forall s \in S$ 


$$
P S_{p c, t, s}^{L o w}-P S_{p c, t, s-1}^{L o w}-S U C_{p c, t, s} \leq 0
$$

$\forall p c \in P C ; \forall t \in T ; \forall s \in S$

$$
C_{p c, t, s-1, s}^{L C}=S U C_{p c, t, s} \cdot C_{p c, t}^{S u p} \cdot Z_{s}
$$

$\forall t \in T ; \forall s \in S ; \forall p c \in P C$

Data for real start-up costs are rare as most power plant operators consider them as confidential. Intertek APTECH has derived lower bounds for start-up costs of coal and gas power plants [36]. The lower bound for depreciation costs of a hot start (which are of interest within this study) are given at $54 \$ / \Delta \mathrm{MW}$ for a large supercritical coal unit. Costs for a CCGT plant are at $35 \$ / \Delta \mathrm{MW}$. According to Kumar et al. [6], there are, in addition, fuel costs and other start-up costs such as costs for auxiliary power or chemicals, water, etc. The fuel costs are given with about $3 \mathrm{MW}_{\mathrm{th}} / \Delta \mathrm{MW}$ for a supercritical coal unit and about 0.056 $\mathrm{MW}_{\mathrm{th}} / \Delta \mathrm{MW}$ for a CCGT plant. Other start-up costs sum up to another $5.81 \$ / \Delta \mathrm{MW}$ for coal units. These numbers would in total result in minimum start-up costs for a hot start of at least $105 \$ / \Delta \mathrm{MW}^{3}$ for a coal unit and at least $37 \$ / \triangle \mathrm{MW}$ for a CCGT unit. Modern generation units are assumed to have slightly lower costs [6]. Start-up-related costs used by other studies are much lower. Maiborn et al. [23], for example, only consider fuel-related start-up costs with $3.56 \mathrm{MW}_{\mathrm{th}} / \Delta \mathrm{MW}$ for coal units and 1.5-1.7 $\mathrm{MW}_{\mathrm{th}} / \Delta \mathrm{MW}$ for CCGT units. With the fuel prices given by [25], this results in start-up costs of about $54 \$ / \Delta \mathrm{MW}$ for coal units and 49-56 \$/DMW for CCGT units. Depreciation costs are not considered and costs for additional $\mathrm{CO}_{2}$ emissions are also neglected. The first Dena grid study [37], on the other hand, also considers depreciation costs for cold starts, but only assumes costs of about $5 € / \Delta \mathrm{MW}$ for a coal unit and $10 € / \Delta \mathrm{MW}$ for a CCGT unit. Values for a hot start are not given but should be somewhat lower.

This broad range of estimates shows that it is a difficult task to assess the real costs. Especially for lignite units, rarely any published values are available. In order to have a unified approach for units of all fuel types and to take the efficiency of the generation units and the current fuel prices into consideration, startup costs used in PERSEUS-NET-TS are calculated by the following equation:

$$
C_{p c, t}^{S u p}=M P S_{p c, t, s} \cdot C a p_{u, t}^{T o t} \cdot D o_{p c}^{M i n} \cdot\left(C_{p c, t}^{V a r}+\frac{C_{i p, p d, e c, t}^{F u e l}}{\eta_{p c, t}}\right)
$$

$\forall p c \in P C_{u} ; \forall u \in U_{t h} ; \forall t \in T$

The equation states that the start-up costs of a process equal the costs that would occur if the unit was operated at the minimum power for a time as long as the minimum down-time. Fuel and variable costs for this time are accounted for. Accordingly, it is only worth to stop a running process and to pay the start-up costs the next time the unit is turned on, if the unit is at least turned off for the minimum down-time. Through this approach, start-up costs in the range of 27 and 50 \$/MW are assigned to the coal units mapped in PERSEUS-NET-TS, depending on their efficiency. CCGT units have start-up costs between 17 and 28 \$/MW and lignite units between 56 and 76 \$ $/ \mathrm{MW}$. In comparison to the values used in other studies, especially in [6], the start-up costs might be underestimated by this approach. However, the dispatch of specific generation units in an energy system model such as PERSEUS-NET-TS might be more realistic,

${ }^{3} 54 \$ / \mathrm{MW}+3 \mathrm{MW}_{\mathrm{th}} / \mathrm{MW} \cdot 15,16 \$ / \mathrm{MW}_{\text {th,col }}[21]+5,81 \$ / \mathrm{MW}=105 \$ / \mathrm{MW}$ 
Postprint of the article How to model the cycling ability of thermal units in power systems? in Energy, 103, 397-409. doi:10.1016/i.energy.2016.02.142

as every unit with a specific efficiency has specific start-up costs. Accordingly, newer efficient units adjust their power at lower costs than older ones. Additionally, fuel price changes are accounted for and values for lignite generation units could be derived.

\section{Results}

For evaluation of the different methods of depicting the cycling ability of thermal units, first cumulated results for all German generation units are given. Next, the dispatch of exemplary individual units is analyzed before the model characteristics and the calculation times for solving the optimization problems corresponding to the different methods are given.

\subsection{Cumulated results for germany}

In order to evaluate the way the different costs and model techniques influence the dispatch of the different generation units, the dispatches of the five techniques are compared to one another and to a dispatch without considering any costs or restrictions of the cycling ability (M0).

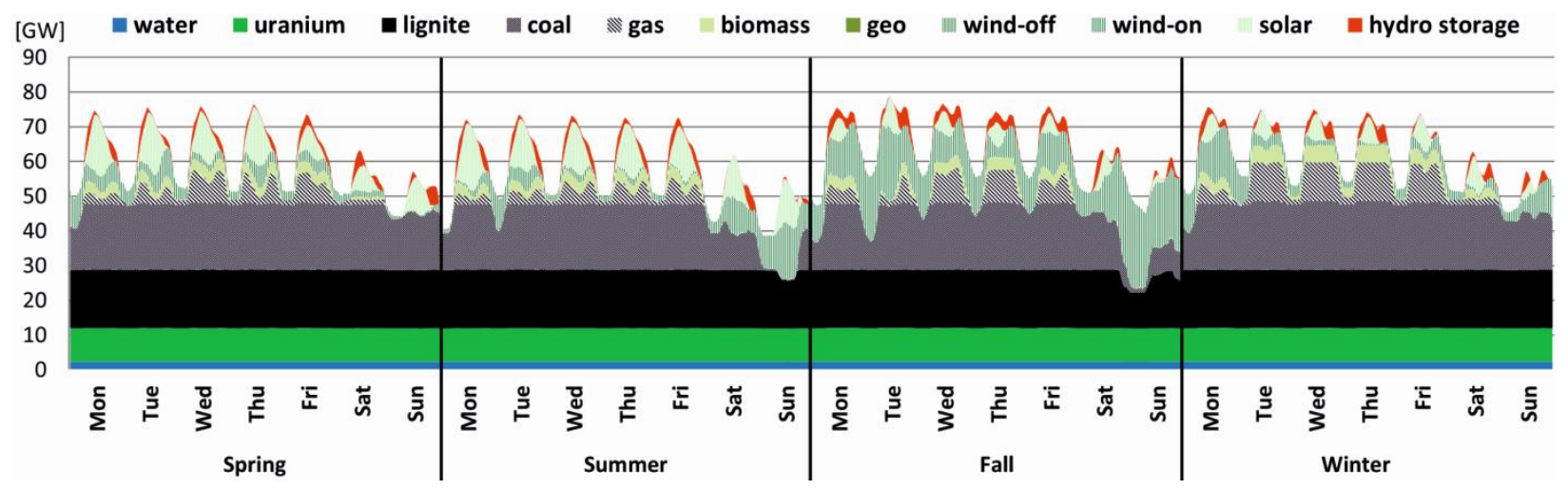

Fig. 3 Electricity generation without consideration of cycling costs or restrictions

Table 1 Electricity generation from thermal units

\begin{tabular}{llccccc} 
& \multicolumn{1}{c}{$[\mathrm{TWh} /$ year] } & \multicolumn{3}{c}{ Gas } \\
& (average generation in $[\mathrm{GW}])$ & Lignite & Coal & CCGT & turbines & Total \\
\hline \multirow{2}{*}{ M1: } & Minimum power & 145.5 & 146.4 & 18.7 & 10.5 & 321.0 \\
& & $(16.6)$ & $(16.7)$ & $(2.1)$ & $(1.2)$ & $(36.6)$ \\
M2: & Minimum power, up- and down & 145.5 & 146.4 & 18.7 & 10.5 & 321.0 \\
& times & $(16.6)$ & $(16.7)$ & $(2.1)$ & $(1.2)$ & $(36.6)$ \\
M3: & Costs on all load changes & 145.5 & 146.2 & 18.8 & 10.5 & 321.0 \\
& & $(16.6)$ & $(16.7)$ & $(2.1)$ & $(1.2)$ & $(36.6)$ \\
M4: & Start-up costs & 145.6 & 145.8 & 19.3 & 10.5 & 321.2 \\
& & $(16.6)$ & $(16.7)$ & $(2.2)$ & $(1.2)$ & $(36.7)$ \\
M5: & Combination of start-up costs & 145.6 & 145.9 & 19.2 & 10.5 & 321.2 \\
& with costs on all load changes & $(16.6)$ & $(16.7)$ & $(2.2)$ & $(1.2)$ & $(36.7)$ \\
\hline \multirow{2}{*}{ M0: } & No consideration of cycling & 145.5 & 146.4 & 18.7 & 10.5 & 321.0 \\
& costs or restrictions & $(16.6)$ & $(16.7)$ & $(2.1)$ & $(1.2)$ & $(36.6)$
\end{tabular}


Electricity generation has to meet the demand at any time. In the PERSEUS-NET-TS model, this is achieved through a mix of renewable and fossil-fueled generation units (cf. Fig. 3). Despite the differences in the modeling of the cycling ability, the total electricity generated from coal, lignite and gas generation units is about $321 \mathrm{TWh}$ for all approaches (cf. Table 1). Gas turbines, which in this analysis are not affected by any kind of cycling costs or restrictions because of insufficient data, generate the same amount of electricity for all approaches. Due to their low variable and fuel costs, lignite units are clearly used as base load units. Only on the weekends in summer and fall when there is a high feed-in from wind and at the same time a relatively low demand, the lignite generation is slightly reduced (cf. Fig. 3).

Comparing the resulting dispatches of the five modeling techniques to the dispatch without consideration of any cycling costs or restrictions, the strongest influence of one of the model techniques can be found for M5 e the combination of start-up costs and costs on all load changes (cf. Table 2). The weighted sum of the absolute deviations of the unit dispatch between the results of one of the modeling techniques and the model run without consideration of any cycling costs or restrictions (M0) is highest for this approach for every energy carrier.

The root-mean-square deviation (square root of the sum of all squared deviations over time divided by $8,760 \mathrm{~h}, \mathrm{RSMD}$ ) over one year shows minimal average deviation of the dispatch between $0.01 \mathrm{GW}$ for lignite power plants calculated with the approach that only considers the minimum power (M1) to maximal average deviations of $1.27 \mathrm{GW}$ for the total dispatch calculated with the combination of start-up costs with costs on all load changes (M5). The mean absolute deviation (sum of absolute differences over time divided by $8,760 \mathrm{~h}, \mathrm{MAD}$ ) shows similar values between $0.00 \mathrm{GW}$ for lignite power plants and the minimum power approach (M1) to maximal average deviations of $0.9 \mathrm{GW}$ for the total dispatch calculated with the combination of start-up costs with costs on all load changes (M5). The mean percentage deviation (sum of percentage differences over time divided by $8,760 \mathrm{~h}$, MPD) shows significant lower values ranging from $0.00 \mathrm{GW}$ for lignite power plants in all approaches (M1-M5) up to maximal percentage average deviations of $0.41 \mathrm{GW}$ for CCGT power plants calculated with the combination of start-up costs with costs on all load changes (M5). Hence, the percentage values highlight the marginal impact from the modeling approach (M1eM5) on the overall results.

Also notable is that start-up costs (M4) have a bigger influence than costs on all load changes (M3) and that the application of either costs has a stronger influence on the cumulated dispatch than the application of a minimum power in combination with minimum up- and down-times (M2).

Table 2 Deviations between the dispatch of the modeling techniques and dispatch without consideration of restrictions or costs of load changing

Sum of weighted absolute

deviation in [GWh/year]

(RSMD)

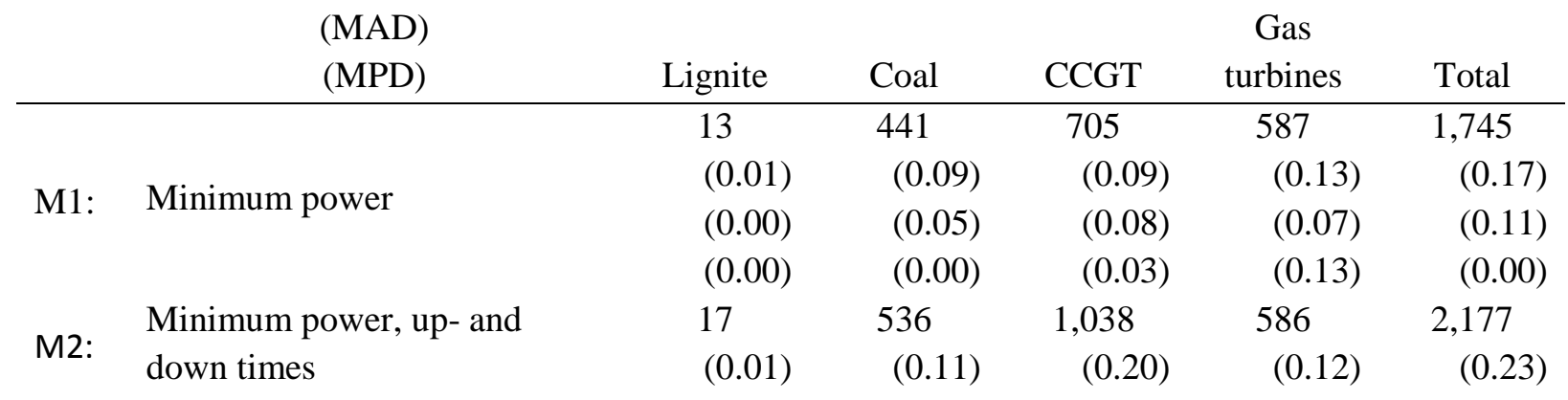


Postprint of the article How to model the cycling ability of thermal units in power systems? in Energy, 103, 397-409. doi:10.1016/i.energy.2016.02.142

\begin{tabular}{|c|c|c|c|c|c|c|}
\hline & & $(0.00)$ & $(0.06)$ & $(0.12)$ & $(0.07)$ & $(0.15)$ \\
\hline & & $(0.00)$ & $(0.01)$ & $(0.05)$ & $(0.13)$ & $(0.00)$ \\
\hline & & 232 & 2,567 & 4,604 & 2,257 & 9,660 \\
\hline & Cocts on oll lood chonges & $(0.16)$ & $(0.45)$ & $(0.91)$ & $(0.51)$ & $(0.87)$ \\
\hline IVI3: & costs on all load cnanges & $(0.03)$ & $(0.29)$ & $(0.53)$ & $(0.26)$ & $(0.58)$ \\
\hline & & $(0.00)$ & $(0.02)$ & $(0.22)$ & $(0.22)$ & $(0.02)$ \\
\hline & & 367 & 3,027 & 6,116 & 2,903 & 12,513 \\
\hline & Start-un costs & $(0.21)$ & $(0.61)$ & (1.11) & $(0.62)$ & (1.11) \\
\hline IV14: & start-up costs & $(0.04)$ & $(0.35)$ & $(0.71)$ & $(0.33)$ & $(0.76)$ \\
\hline & & $(0.00)$ & $(0.05)$ & $(0.40)$ & $(0.29)$ & $(0.02)$ \\
\hline & & 372 & 3,535 & 6,618 & 2,874 & 13,398 \\
\hline & Combination of start-up costs & $(0.22)$ & $(0.68)$ & (1.19) & $(0.62)$ & (1.27) \\
\hline 1015 & with costs on all load changes & $(0.04)$ & $(0.40)$ & $(0.76)$ & $(0.33)$ & $(0.90)$ \\
\hline & & $(0.00)$ & $(0.05)$ & $(0.41)$ & $(0.27)$ & $(0.03)$ \\
\hline
\end{tabular}

As the lignite generation does not change often within the considered time frame (cf. Fig. 4), it is not surprising that there are no big differences due to the different modeling techniques of the cycling ability.

For the dispatch of the coal units, on the other hand, this is more surprising as there are some changes in the generation level during the considered time slots (cf. Fig. 5). However, from the cumulated point of view of summing up all German coal generation units, there are no major differences to be seen (cf. Table 2 and Fig. 5).

For the dispatch of the CCGT units and the gas turbines, some differences become apparent (cf. Figs. 6 and 7): The application of costs on all load changes (M3) or start-up costs (M4) reduces the cycling of the CCGT units compared to the other approaches (M0, M1 and M2). For example, generation during the day in the summer week is not reduced over noon. This seems to be mainly compensated through a partially increased generation (and cycling) of the gas turbines (cf. Fig. 7) with these two approaches (M3 and M4). For a combined application of start-up costs and costs on all load changes (M5), the sum of the weighted absolute derivations of the cumulated generation level of CCGT units amounts to $6618 \mathrm{GWh}$ per year. As the mean generation for CCGT units only amounts to about $2.2 \mathrm{GW}$ (cf. Table 1), this derivation is quite high.

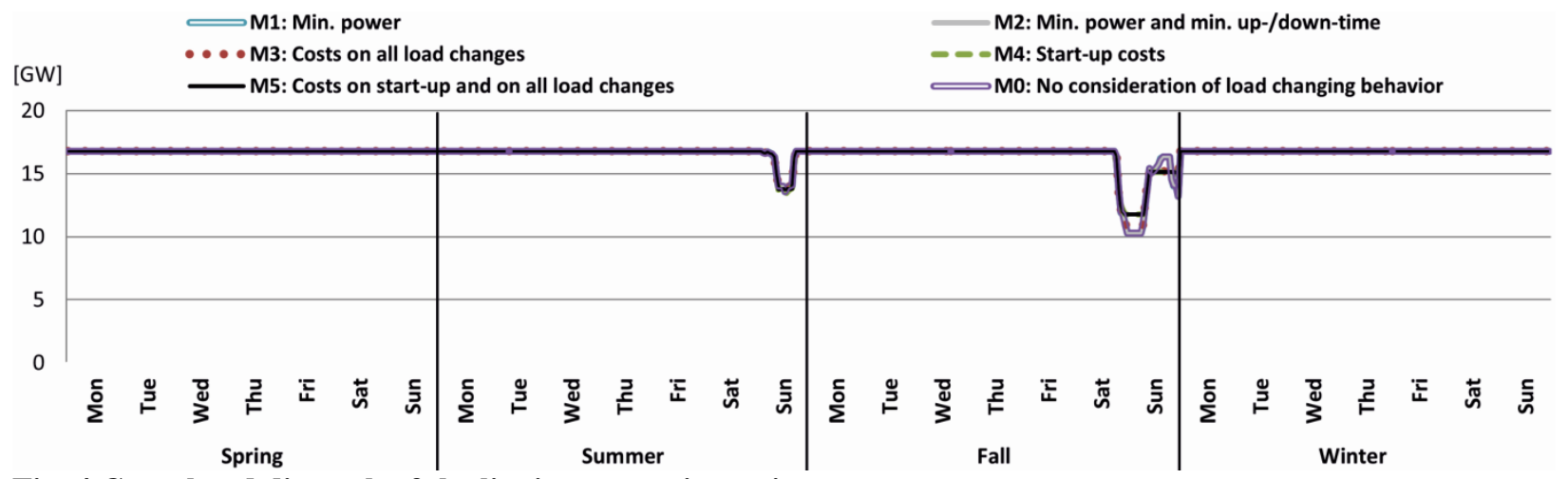

Fig. 4 Cumulated dispatch of the lignite generation units 


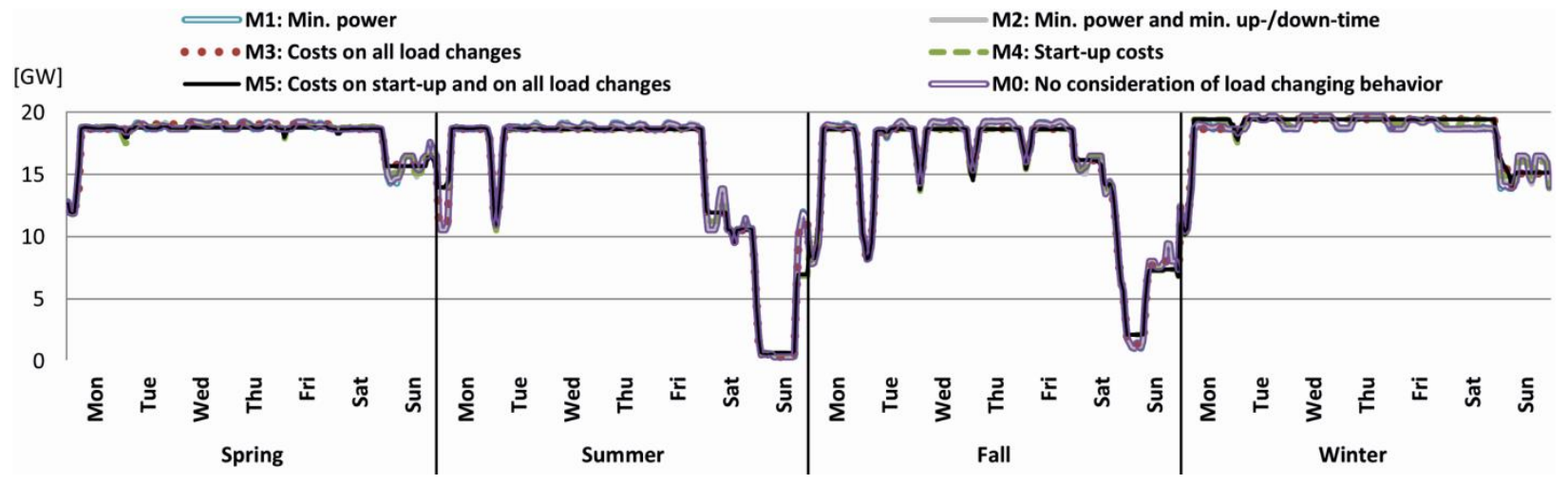

Fig. 5 Cumulated dispatch of the coal generation units

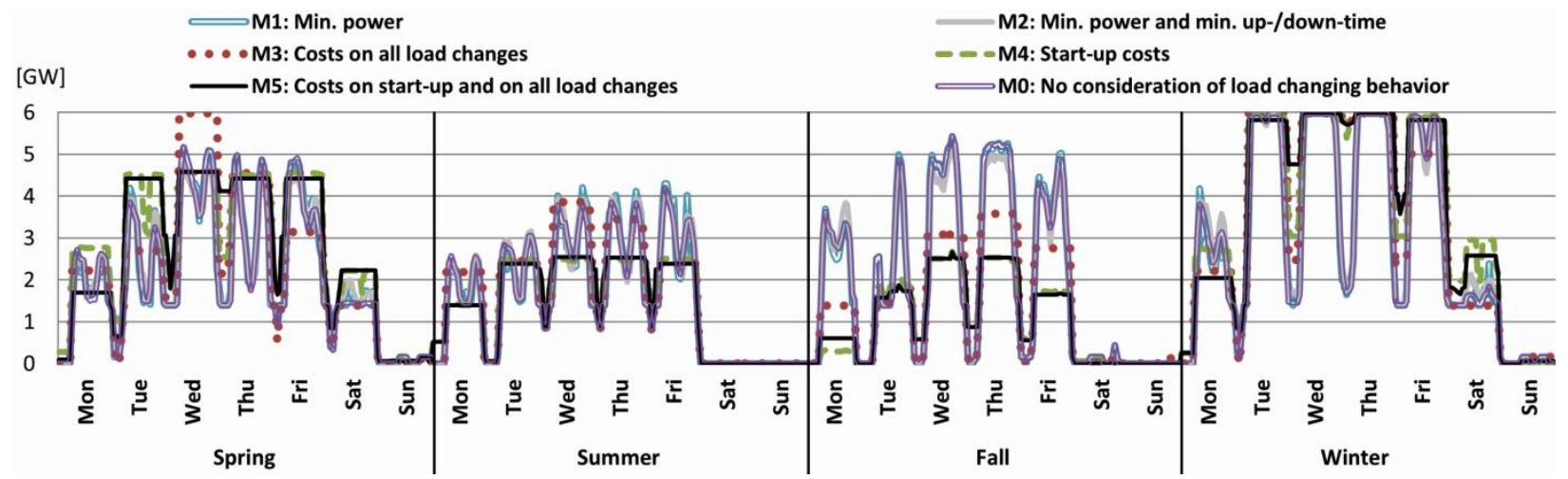

Fig. 6 Cumulated dispatch of the CCGT units

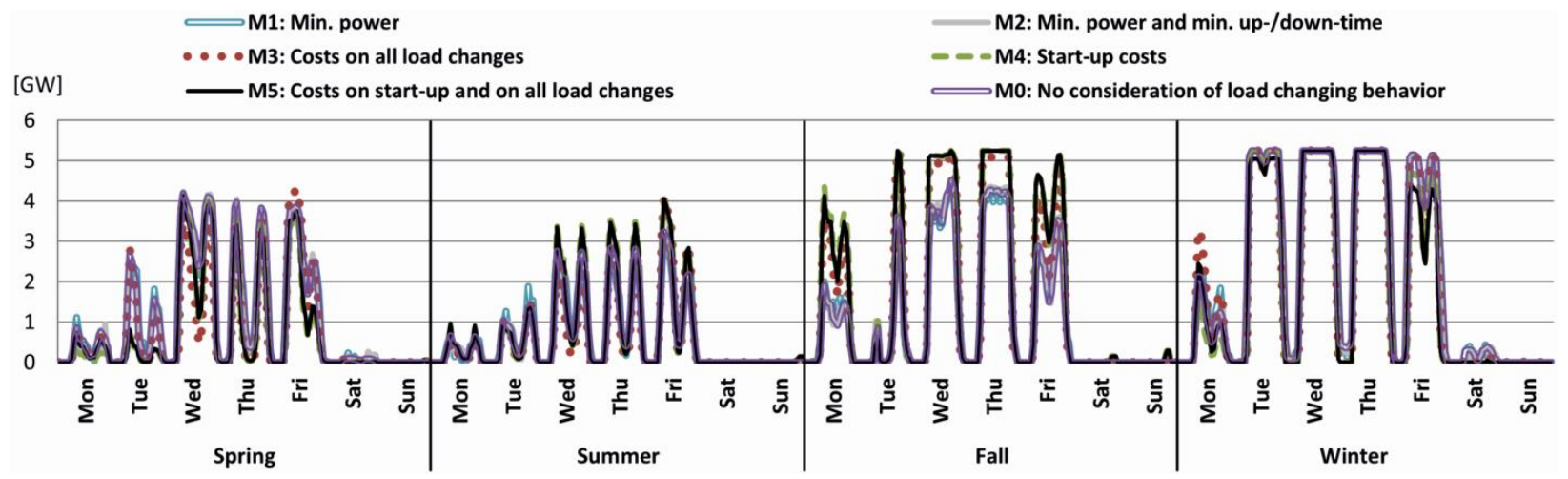

Fig. 7 Cumulated dispatch of the gas turbines

\subsection{Resulting dispatch of exemplary single generation units}

While differences in the cumulated dispatch of coal units seem to be little, this might be different for single generation units. As an example, the resulting dispatch of a specific coal unit (Heilbronn, block 6) is analyzed in detail for the summer and the winter week (cf. Figs. 8 and 9).

The most on/off cycling takes place with the approach that only considers the minimum power (M1). In this case, the generation unit is turned on and off 19 times during the summer week (cf. Fig. 8) and 12 times during the winter week (cf. Fig. 9). The additional application of minimum up- and down-times (M2) reduces the on/off cycling to 9 and 8 times. During the summer week, no generation occurs at this unit for 
Postprint of the article How to model the cycling ability of thermal units in power systems? in Energy, 103, 397-409. doi:10.1016/i.energy.2016.02.142

the approaches that apply cost (M3, M4, and M5). When no costs and restrictions are applied to the cycling, the unit generates during day time at working days, but often below the minimum power of $41 \mathrm{MW}$. With the approaches that apply start-up costs (M4 and M5), the generation of the unit does not drop below the minimum power in winter, but on Sunday. While the approach that only applies start-up costs (M4) reduces the generation during most nights to the minimum power, this is only true on Monday night for the combination of start-up costs and costs on all load changes (M5).

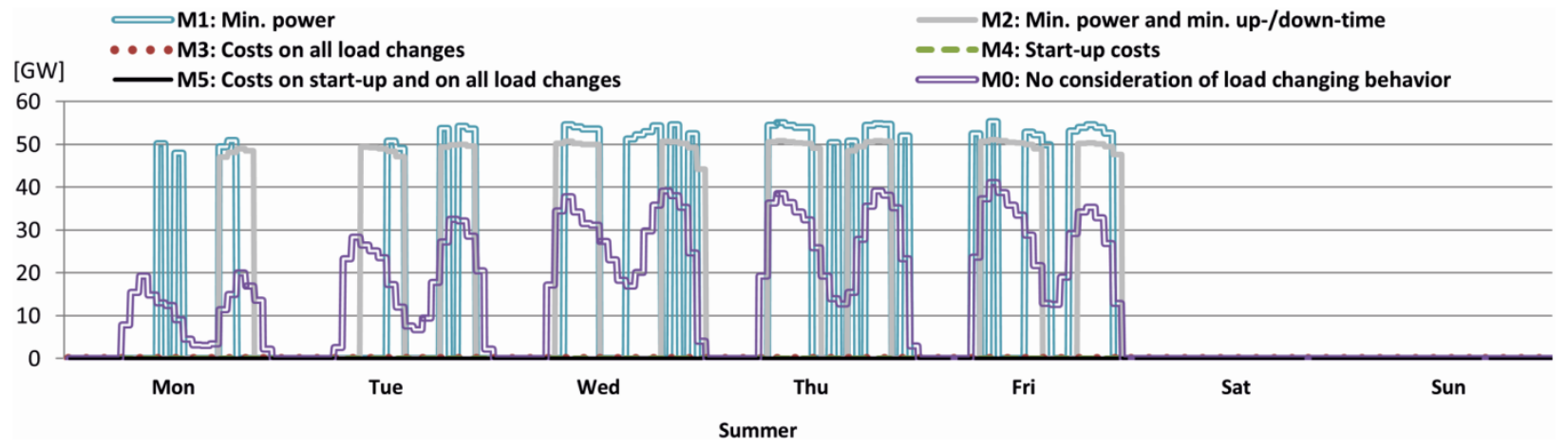

Fig. 8 Dispatch of a coal generation unit during summer

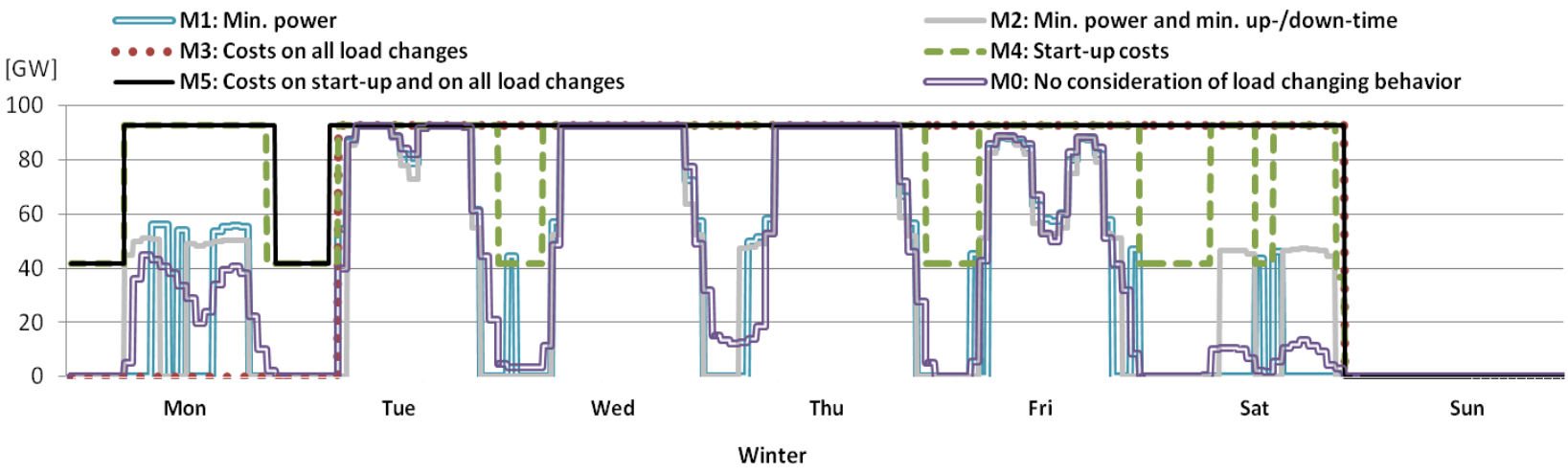

Fig. 9 Dispatch of a coal generation unit during winter

Other effects may be recognized by looking at the resulting dispatch of a specific CCGT unit (Kirchmoser)€. During the summer week (cf. Fig. 10), the approach with costs on all changes (M3) significantly reduces cycling compared to the approaches without costs (M0, M1, M2). Peak loads are not followed and the generation is not reduced during noon. Also, the on/off cycling only amounts to three compared to 13 times for the approach that only applies the minimum power (M1). For the combination of mini-mum power and minimum up- and down-times, nine on/off cycles can be counted. While the process generates electricity at each working day and is turned off during the night when no costs or restrictions are applied to the cycling (M0), this is different when start-up costs are applied (M4). In this case, electricity is generated only from Tuesday to Friday and during night time, the process is not completely turned off. However, this generation takes place below the minimum power of about $65 \mathrm{MW}$. When start-up costs and costs on all load changes are applied (M5), no generation and thus no cycling takes place during the summer week. 
During the winter week (cf. Fig. 11), the cycling is reduced most for the approaches that apply costs on all load changes (M3 and M5). The combined-cycle unit is turned on only once and generates electricity from Tuesday to Friday. For the approach only considering start-up costs (M4), the on/off cycling is also reduced to one, but the generation continues on until Saturday whereas the load drops below the minimum power during the night between Friday and Saturday and on Saturday noon. For the approaches that do not apply any costs (M0, M1 and M2), the number of on/off cycles is between six (M0) and 16 (M1).

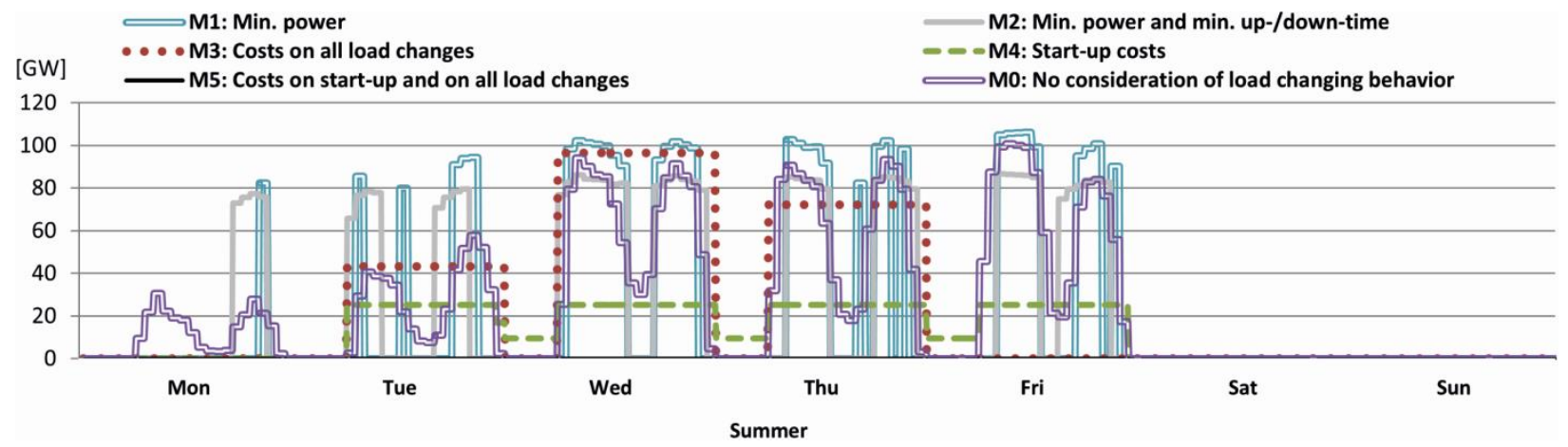

Fig. 10 Dispatch of a CCGT unit during summer

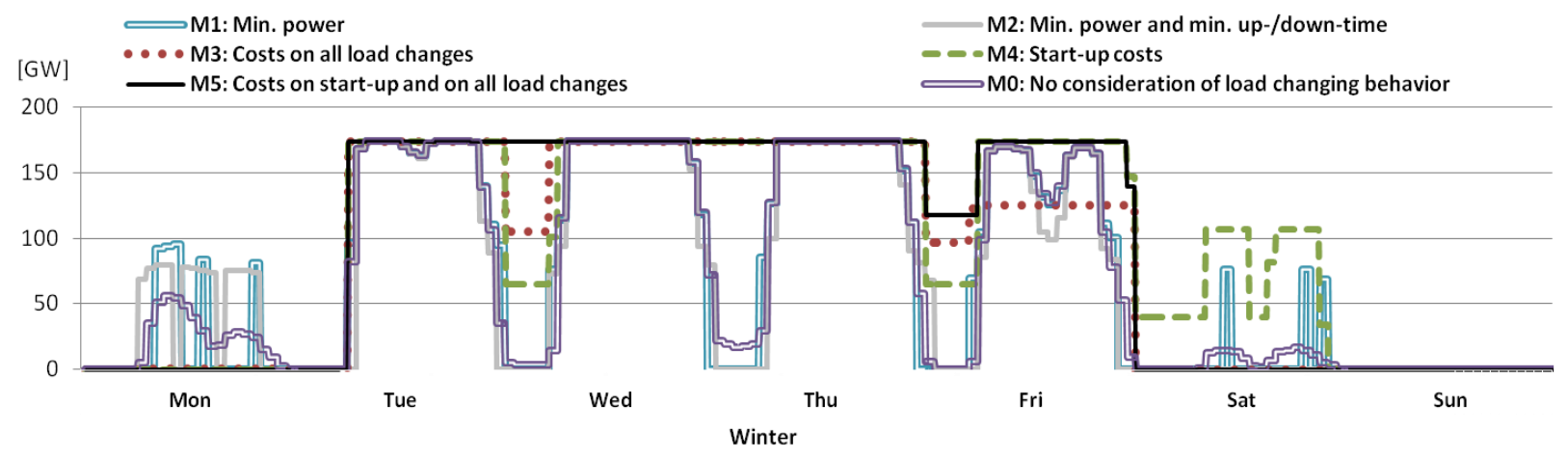

Fig. 11 Dispatch of a CCGT unit during winter

For the PERSEUS-NET-TS model, the on/off cycling of specific generation units is better reduced by any approach that applies some sort of costs to load changes than by approaches that limit the generation units' operations purely by considering the minimum power with or without minimum up- and downtimes. This is conclusive for any cost-minimizing model as the application of a minimum power (without costs) is not mirrored in the objective function. Consequently, the number of on/off cycles does not influence the total costs.

\subsection{Model characteristics}

When optimizing energy system models, the calculation time is of high importance [24]. The number of considered time slots, respectively hours, for example, is always a compromise between precision and calculation time. For the considered approaches, the optimization problem is smallest for the approach without consideration of cycling costs or restrictions (M0). 3.59 million Equations, 3.12 million variables, and 12.31 million non-zero elements are considered (cf. Table 3). The calculation time to solve the optimization problem was 229 s on six threads on a computer with Windows Server 2008 R2 Enterprise, Intel(R) Xeon(R) CPU E5-1650@ 3.20 GHz; 96 GB RAM; 64 Bit. The problems based on the approach with costs on all load variations (M3) and based on start-up costs (M4) are of similar size. The problem 
Postprint of the article How to model the cycling ability of thermal units in power systems? in Energy, 103, 397-409. doi:10.1016/i.energy.2016.02.142

with costs on all load changes has 12.99 million non-zero elements and the problem based on start-up costs has about 13.19 million non-zero elements. Consequently, the calculation time for the problems based on these two approaches is slightly higher. The optimization problem of PERSEUS-NET-TS based on these approaches (M0, M3, M4 and M5) is linear and is solved with the barrier algorithm. With the integration of the minimum power, on the other hand, the problem becomes mixed-integer linear. Accordingly, the calculation time is much higher. The problem based on the minimum power (M1) has 3.78 million Equations, 3.24 million variables, and 12.76 million non-zero elements. However, it is more important that it has 112,896 binary variables. Consequently, the problem has to be solved through some sort of branch \& bound or branch \& cut algorithm [38]. The time to solve the PERSEUS-NET-TS problem is about factor 10 as high as for the linear problems. The computation time to solve the approach that combines the minimum power with minimum up- and down-times (M2) is again higher by at least a factor of 10 .

Table 3 Characteristics of the optimization problem for the different modeling techniques

\begin{tabular}{|c|c|c|c|c|c|c|}
\hline & & Equations & Variables & $\begin{array}{l}\text { Non-zero } \\
\text { elements }\end{array}$ & $\begin{array}{c}\text { Binary } \\
\text { variables }\end{array}$ & $\begin{array}{l}\text { Time the solver used } \\
\text { to solve the model in } \\
\text { CPU seconds } \\
\text { (exemplary values) }\end{array}$ \\
\hline M1: & Minimum power & 3.78 Mio. & 3.24 Mio & 12.76 Mio & 112,896 & $4,462 \mathrm{sec}$ \\
\hline M2: & $\begin{array}{l}\text { Minimum power, up- } \\
\text { and down times }\end{array}$ & 3.93 Mio & 3.24 Mio & 13.7 Mio & 112,896 & $49,883 \mathrm{sec}$ \\
\hline M3: & $\begin{array}{l}\text { Costs on all load } \\
\text { changes }\end{array}$ & 3.66 Mio. & 3.41 Mio. & 12.99 Mio. & - & $246 \mathrm{sec}$ \\
\hline M4: & Start-up costs & 3.82 Mio. & 3.40 Mio. & 13.19 Mio. & - & $296 \mathrm{sec}$ \\
\hline M5: & $\begin{array}{l}\text { Combination of start-up } \\
\text { costs with costs on all } \\
\text { load changes }\end{array}$ & 3.9 Mio. & 3.6 Mio. & 13.8 Mio. & - & $336 \mathrm{sec}$ \\
\hline M0: & $\begin{array}{l}\text { No consideration of } \\
\text { cycling costs or } \\
\text { restrictions }\end{array}$ & 3.59 Mio. & 3.13 Mio. & 12.31 Mio. & - & $229 \mathrm{sec}$ \\
\hline
\end{tabular}

\subsection{Critical Reflection}

Even though that the outcomes of the PERSEUS-NET-TS model is compared to each other, it was not possible to validate the considered approaches with empiric data for the cycling restrictions. As the used model considers all generation units (>100 MW) that exist in Germany as well as the transmission grid, it has too many variables to consider $8760 \mathrm{~h}$ per year. Therefore, time slots representing average conditions have to be used to depict the year. A comparison with real dispatch data might validate the dispatch data. However, due to the fact that the pure differences in the applied approaches are analyzed in this paper, this empirical comparison is resigned here. In the empirical data, further strategic and other (time- and localdependent) technological aspects might have additional impacts too, which could not be fully assessed with optimization models. Furthermore, this will draw the attention away from the pure comparison of modeling approaches conducted in this paper. Future studies of implementing cycling restrictions might therefore focus on a smaller real-energy system where the dispatch of each single generation unit, the specific electricity demand, and the specific renewable feed-in at each grid node as well as electricity imports and exports are known for each hour. Additionally, for all considered approaches, but may be for the minimum power, there is the problem of finding realistic data for the cycling restrictions. Values in the literature for 
load-changing costs or for the minimum up- and down times differ rather strongly. Conse-quently, it could unfortunately not be determined whether and to what extent the implemented costs and restrictions on load changes of any modeling technique are realistic. However, results of the analysis conducted in this paper still allow drawing general conclusions on the effects different modeling techniques have on the modeled system.

It has to be noted that there might be other approaches to modeling cycling ability of thermal units that are not considered here. In case that calculation time is not a majorly limiting factor, a combination of startup costs and minimum up- and down-times might for example be a suitable solution.

Furthermore, the presented results are limited to the unit commitment problem. If additionally, a linear investment decision for new units is part of the optimization, the description of the cycling ability of these new units is not possible with minimum up-and down times or start-up costs, since no minimum power can be determined linearly without the knowledge of the installed capacity. In this case, a description of the cycling ability of these new units through costs on all load changes might still be a sufficient approximation.

\section{Conclusions}

The considerable share of electricity generation units based on volatile renewable energy sources in the future energy system leads to an increasing requirement for fossil-fuel-based units to cope with fluctuations of the residual load. This challenge is analyzed widely in literature by a multitude of energy system models, which apply different techniques to model the cycling ability of thermal power plants. These models do, however, not compare different techniques. Therefore, five techniques to model the cycling ability of thermal power plants are implemented in the existing grid node-specific energy system model PERSEUSNET-TS in order to identify differences in unit commitment and computing time. The results are compared to each other and to the optimization problem without consideration of any restrictions or costs for cycling (M0).

With the PERSEUS-NET-TS model, the implementation of any cycling costs (M3 to M5) has a larger impact on the cumulated dispatch of all German thermal units than the mixed-integer implementation of a binding minimum power with or without considering minimum up- and down-times (M1 and M2). However, for the cumulated dispatch of lignite and coal units, the effect of cycling costs is quite small and seems negligible. Consequently, in energy system models that do not map specific generation units, but sum up many units to one unit per technology class, it might not be justified to restrict the flexibility of the cumulated dispatch of the lignite and coal unit class because according to this findings there is hardly any impact on the aggregated results.

Despite, there can be major differences in the dispatch of single units. As shown for the example of two specific generation units, the most on/off cycling occurs with the approach that only con-siders the minimum power (M1). The application of minimum up-and down times (M2) reduces the cycling considerably, but not as much as the application of either start-up costs (M4) or costs on all load changes (M3). Obviously, the combination of these linear approaches reduces cycling the most (M5).

The description of the cycling ability of thermal units through a minimum power, minimum up- and down times (M2), based on a mixed-integer problem, is widely used in energy system modeling. However, besides not significantly reducing the on/off cycling of single generation units, this modeling technique has the disadvantage of a comparatively high computing time. Consequently, in optimizing dispatch models 
Postprint of the article How to model the cycling ability of thermal units in power systems? in Energy, 103, 397-409. doi:10.1016/i.energy.2016.02.142

which are limited by computing time, a linear description of the cycling ability of thermal units seems favorable. In this context, the linear implementation of start-up costs in combination with costs on all load changes (M5) is a feasible solution.

The description of the cycling ability of thermal units through a minimum power, minimum up- and down times (M2), based on a mixed-integer problem, is widely used in energy system modeling. However, besides not significantly reducing the on/off cycling of single generation units, this modeling technique has the disadvantage of a comparatively high computing time. Consequently, in optimizing dispatch models which are limited by computing time, a linear description of the cycling ability of thermal units seems favorable. In this context, the linear implementation of start-up costs in combination with costs on all load changes (M5) is a feasible solution.

\section{Appendix}

Nomenclature:

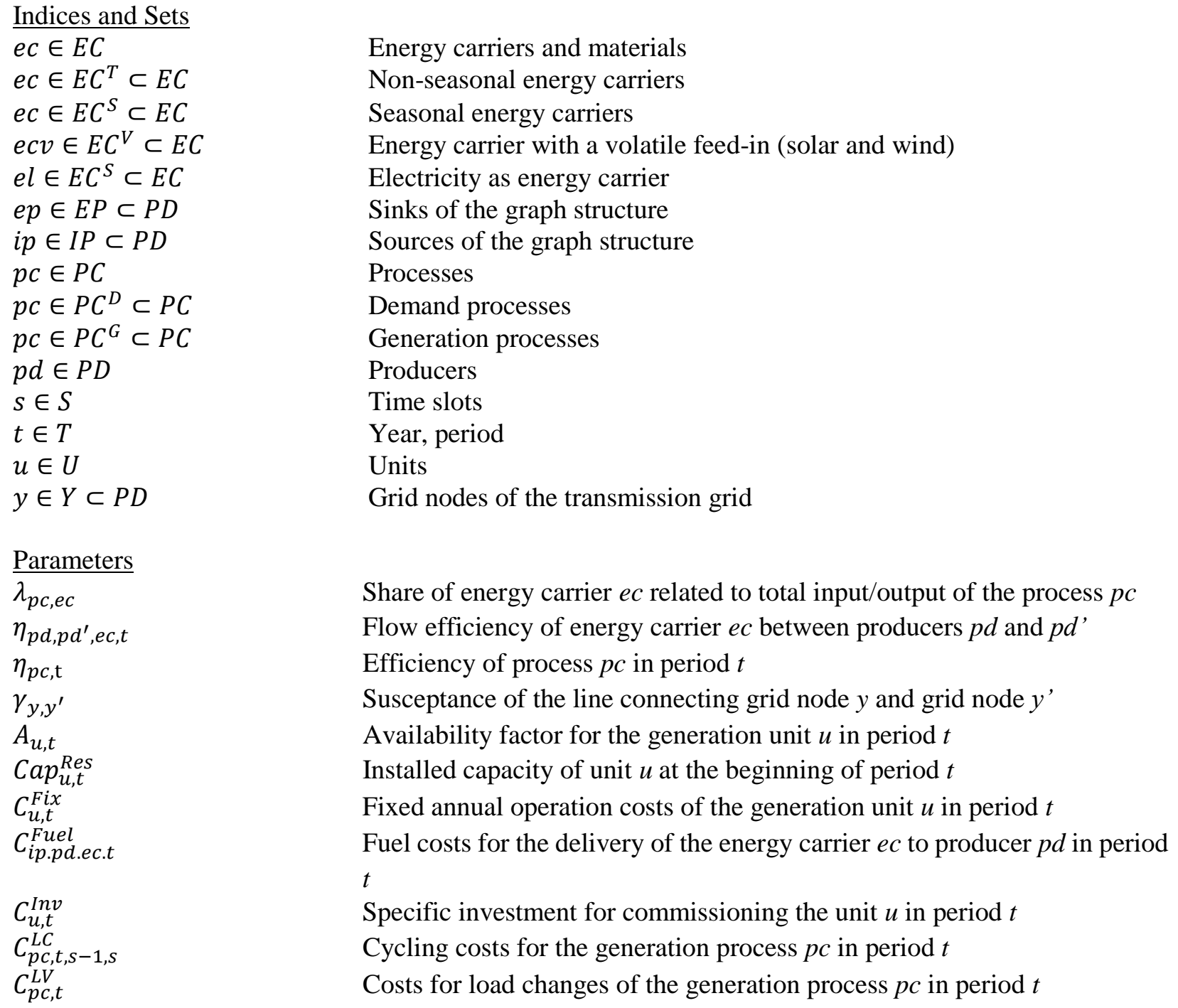

Share of energy carrier $e c$ related to total input/output of the process $p c$ Flow efficiency of energy carrier $e c$ between producers $p d$ and $p d$ ' Efficiency of process $p c$ in period $t$

Susceptance of the line connecting grid node $y$ and grid node $y$ '

Availability factor for the generation unit $u$ in period $t$

Installed capacity of unit $u$ at the beginning of period $t$

Fixed annual operation costs of the generation unit $u$ in period $t$

Fuel costs for the delivery of the energy carrier $e c$ to producer $p d$ in period

$t$

Specific investment for commissioning the unit $u$ in period $t$

Cycling costs for the generation process $p c$ in period $t$

Costs for load changes of the generation process $p c$ in period $t$ 


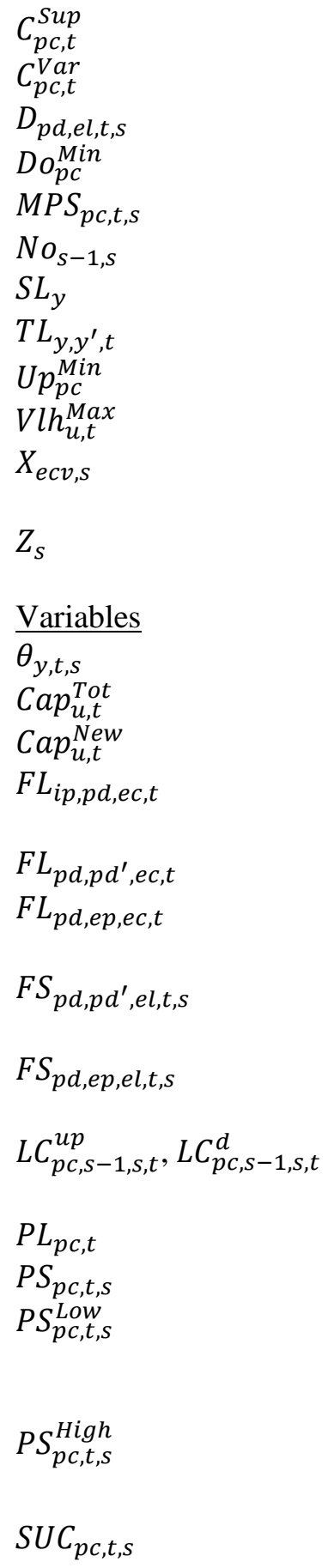

Start-up costs of the generation process $p c$ in period $t$

Variable operating costs of the process $p c$ in period $t$

Demand of producer $p d$ for electricity $e l$ in time slot $s$ in period $t$

Minimum down-time of process $p c$

Minimum power of process $p c$ in time slot $s$ in period $t$

Quantity of transitions from time slot $s-1$ to $s$ per year

Indicator if grid node $y$ is the slack bus

Thermal limit of the line connecting grid node $y$ and grid node $y$ '

Minimum run time of process $p c$

Maximal full-load hours of unit $u$

Factor for diversification of the feed-in from volatile energy carriers ecv to the time slots $s$ with values $\in[0,1]$

Number of occurrences of the time slot $s$ per year

Phase angle difference at grid node $y$ in time slot $s$

Installed capacity of the generation unit $u$ at the end of period $t$

Newly installed capacity of generation unit $u$ in a period $t$

Level of $e c$-flow from the source ip of the graph structure to producer $p d$ in period $t$

Level of $e c$-flow from producer $p d$ to producer $p d$ ' in period $t$

Level of $e c$-flow from producer $p d$ to the sink $e p$ of the graph structure in period $t$

Level of electricity el flow from producer $p d$ to producer $p d$ ' per time slot $s$ in period $t$

Level of electricity el flow from producer $p d$ to the sink of the graph structure $e p$ per time slot $s$ in period $t$

Positive and negative load change of generation unit $u$ between time slots $s-1$ and $s$ in period $t$

Activity level of process $p c$ per year in period $t$

Activity level of process $p c$ in time slot $s$ in period $t$

Indication of an activity level of process $p c$ between zero and the minimum power in time slot $s$ in period $t$

Indication of an activity level of process $p c$ between the minimum and the maximal power in time slot $s$ in period $t$

Accounts for positive load changes below the minimum power of process

$p c$ in time slot $s$ in period $t$

$\underline{\text { Binary Variables }}$

$G 01_{p c, t, s}$

On/off status of process $p c$ in time slot $s$ in period $t$

\section{Acknowledgements}

Earlier versions of this article appeared in the proceedings of the $37^{\text {th }}$ IAEE Conference. 
Postprint of the article How to model the cycling ability of thermal units in power systems? in Energy, 103, 397-409. doi:10.1016/i.energy.2016.02.142

\section{References}

[1] Huber M, Dimkova D, Hamacher T. Integration of wind and solar power in Europe: assessment of flexibility requirements. Energy 2014;69(1):236e46. http://dx.doi.org/10.1016/j.energy.2014.02.109.

[2] Schroder€ A, Kunz F, Meiss J, Mendelevitch R, Hirschhausen Cv. Current and prospective costs of electricity generation unitl 2050. Berlin, Germany: DIW; 2013. http://www.diw.de/documents/publikationen/73/diw_01.c.424566.de/diw_datadoc_2013-068.pdf.

[3] Kumar N, Paterson S, Coleman K, Lee C, Agan D, Lefton S. Power plant cycling measure e evaluating historical cycling to model future grid operations. In: Power and energy society general meeting (PES), 2013 IEEE, July 21-25, 2013; 2013. p. 1 e5.

[4] Oates DL, Paulina J. Production cost and air emissions impacts of coal cycling in power systems with large-scale wind penetration. Environ Res Lett 2013;8(2). http://dx.doi.org/10.1088/17489326/8/2/024022.

[5]Díaz D. Production cost models with regard to liberalised electricity markets [PhD Thesis]. Germany: Universitat€ Karlsruhe (TH); 2008.

[6]Kumar N, Besuner P, Lefton S, Agan D, Hileman D. Power plant cycling costs. Sunnyval, Calfornia: Intertek APTECH; 2012. http://wind.nrel.gov/public/ wwis/aptechfinalv2.pdf.

[7]Lew D, Brinkman G, Kumar N, Besuner P, Agan D, Lefton S. Impacts of wind and solar on emissions and wear and tear of fossil-fueled generators. In: Power and energy society general meeting, 2012 IEEE, July 22-26, 2012; 2012. p. 1 e8.

[8] Wood AJ, Wollenberg BF, Sheble GB. Power generation, operation, and control. 3rd ed. Hoboken, NJ: WILEY; 2013, ISBN 978-0-471-79055-6.

[10] Fichtner W, Wietschel M, Rentz O. Long term planning of inter-company energy supply concepts. OR Spectr 2002;24(4):497e520. http://dx.doi.org/ 10.1007/s00291-002-0106-2.halilpour R. Multi-level investment planning and scheduling under elec-tricity and carbon market dynamics: retrofit of a power plant with PCC (post-combustion carbon capture) processes. Energy 2014;64(1):172e86. http:// dx.doi.org/10.1016/j.energy.2013.10.086.

[11] Goransson€ L, Goop J, Unger T, Odenberger M, Johnsson F. Linkages between demand-side management and congestion in the European electricity trans-mission system. Energy 2014;69(1):860e72. http://dx.doi.org/10.1016/ j.energy.2014.03.083.

[12] Chakraborty S, Ito T, Senjyu T, Saber AY. Unit commitment strategy of thermal generators by using advanced fuzzy controlled binary particle swarm opti-mization algorithm. Int J Electr Power \& Energy Syst 2012;43(1):1072e80. http://dx.doi.org/10.1016/j.ijepes.2012.06.014.

[13] Hundt M, Barth R, Sun N, Wissel S, Voß A. Compatibleness of renewable en-ergy and nuclear energy in the generation portfolio (in German). Stuttgart, Germany: Institut für Energiewirtschaft und Rationelle Energieanwendung, IER; 2009.

[14] Kovacevic R, Paraschiv F. Medium-term planning for thermal electricity pro-duction. OR Spectr 2014;36(3):723e59. http://dx.doi.org/10.1007/s00291-013-0340-9.

[15] Eßer-Frey A. Analyzing the regional long-term development of the German power system using a nodal priceing approach [PhD Thesis]. Germany: Karlsruhe Institute of Technology; 2012.

[16] Warland G, Haugstad A, Huse ES. Including thermal unit start-up consts in a long-term hydrothermal scheduling model. July 14-18, 2008. In: Pro-ceedings of the 16th power system computation conference (PSCC), 1. Glas-gow, Scotland: Curran Associates, Inc; 2008, ISBN 978-1-61738-857-6. p. $808 \mathrm{e} 16$.

[17] Jiang R, Zhang M, Li G, Guan Y. Two-stage network constrained robust unit commitment problem. Eur J Operational Res 2014;234(3):751e62. http:// dx.doi.org/10.1016/j.ejor.2013.09.028.

[18] Norouzi MR, Ahmadi A, Nezhad AE, Ghaedi A. Mixed integer programming of multi-objective security-constrained hydro/thermal unit commitment. Renew Sustain Energy Rev 2014;29(0):911e23. http://dx.doi.org/10.1016/j.rser.2013.09.020.

[19] De Jonghe C, Hobbs BF, Belmans R. Value of price responsive load for wind integration in unit commitment. Power Syst IEEE Trans 2014;29(2):675e85. http://dx.doi.org/10.1109/TPWRS.2013.2283516. 
[20] Yang L, Jian J, Wang Y, Dong Z. Projected mixed integer programming for-mulations for unit commitment problem. Int J Electr Power \& Energy Syst 2014;68:195e202. http://dx.doi.org/10.1016/j.ijepes.2014.12.054.

[21] Govardhan M, Roy R. Economic analysis of unit commitment with distributed energy resources. Int J Electr Power \& Energy Syst 2015;71:1e14. http:// dx.doi.org/10.1016/j.ijepes.2015.01.028.

[22] Arasteh HR, Moghaddam MP, Sheikh-El-Eslami MK, Abdollahi A. Integrating commercial demand response resources with unit commitment. Int J Electr Power \& Energy Syst 2013;51:153e61. http://dx.doi.org/10.1016/j.ijepes.2013.02.015.

[23] Maiborn, P., Barth, R., Brand, H., Hasche, B., Swider, D., Ravn, H., Weber, C. (2008): All Island Grid Study e Wind Variability Management Studies. The Department of Enterprise, T.a.I.a.t.D.o.C., Energy and Natural Resources (ed.). Riso Natrional Laboratory Denmark, IER Stuttgart, RAM-Lose EDB, University Duisburg-Essen, Germany.

[24] Babrowski S, Heffels T, Jochem P, Fichtner W. Reducing computing time of energy system models by a myopic approach - a case study based on the PERSEUS-NET model. Energy Syst 2014;5(1):65e83. http://dx.doi.org/ 10.1007/s12667-013-0085-1.

[25] IEA. World energy outlook. International Energy Agency; 2012.

[26] AGEB. Gross energy demand in Germany in 2012 (in German). Berlin, Ger-many: AG Energiebilanzen e.V; 2013.

[27] Babrowski S. Need and distribution of daily electricity storage systems in the future German energy system (in German) [PhD Thesis]. Germany: Karlsruhe Institute of Technologie; 2015. http://dx.doi.org/10.5445/KSP/1000044722.

[28] Tennet. Empirical solar feed-in 2010 (in German). 2011. http://www.

tennettso.de/site/Transparenz/veroeffentlichungen/netzkennzahlen.

[29] 50Hertz. http://www.50hertz.com/de/unternehmen.htm; 2013.

[30] Amprion. http://www.amprion.de/unternehmen; 2013.

[31] TRANSNET. TRANSNET BW. 2013. http://transnet-bw.de.

[32] Das JC. Power system analysis e short-circuit load flow and harmonics. New York, USA: Marcel Dekker, Inc.; 2001, ISBN 0-8247-0737-0.

[33] Binato S, Pereira MVF, Granville S. A new Benders decomposition approach to solve power transmission network design problems. Power Eng Rev IEEE 2001;21(5). http://dx.doi.org/10.1109/mper.2001.4311380.62e62.

[34] Babrowski S, Jochem P, Fichtner W. Electricity storage systems in the future German energy sector e an optimization of the German electricity generation system until 2040 considering grid restrictions. Comput Operations Res February 2016;66:228e40. http://dx.doi.org/10.1016/j.cor.2015.01.014.

[35] Rosen J. The future role of renewable energy sources in European electricity supply - a modelbased analysis for the EU-15 [PhD Thesis]. Germany: Uni-versity of Karlsruhe; 2008.

[36] Lew D, Brinkman G, Kumar N, Lefton S, Jordan G, Venkataraman S. Finding flexibility: cycling the conventional fleet. Power Energy Mag IEEE 2013;11(6): 20e32. http://dx.doi.org/10.1109/mpe.2013.2277988.

[37] DENA. dena grid study 1. Integration into the national grid of onshore and offshore wind energy generated in Germany by the year 2020. Cologne, Germany: DEWI, E.On, EWI, RWE, Vattenfall; 2005.

[38] Nickel S, Stein O, Waldmann K-H. Operations research. Berlin Heidelberg, Germany: Springer Verlag; 2011, ISBN 978-3-642-22623-6. 